\title{
História cultural dos surdos: desafio contemporâneo
}

\section{Cultural history of the deaf: contemporary challenge}

\author{
Gladis Perlin ${ }^{1}$ \\ Karin Strobel ${ }^{2}$
}

\begin{abstract}
RESUMO
O presente artigo parte da perspectiva da história cultural em direção aos Estudos Surdos. Objetiva debruçar-se em pesquisas teóricas que possibilitem a visão sobre a história cultural a ser captada na vida cotidiana, resistências e fazeres a partir da cultura, em nosso caso, do povo surdo. Nestas pesquisas teóricas observou-se o papel que exerce a cultura surda, permeada pela construção da identidade, pela língua de sinais, pela pedagogia surda. E no contato com a história cultural notamos uma metodologia que ressalta a importância da participação dos povos surdos para sua construção. Esta história faz emergir os saberes em que entram em cena as memórias das experiências do "ser surdo", uma visão abrangente em relação ao que ocorre com o povo surdo, especialmente os corpos amordaçados por políticas institucionais, os embates no campo do colonialismo e dos sistemas opressivos educacionais, as lutas por identidade e por significados culturais. Nestes aportes tornam-se frequentes os indícios de signos e significados subjetivantes. O desafio é construir uma nova história cultural, registrando as lutas pela identidade surda, pela construção da identidade cultural, pelo reconhecimento da língua de sinais, pela emancipação dos sujeitos surdos de todas as formas de opressão e seu livre e espontâneo desenvolvimento, bem como a pedagogia surda presente no povo surdo.
\end{abstract}

Palavras-chave: história; cultura; cultura surda; agentes históricos; subjetividade; empoderamento.

DOI: $10.1590 / 0104-4060.37011$

1 Universidade Federal do Rio Grande do Sul. Porto Alegre, Rio Grande do Sul, Brasil. Av. Paulo Gama, n 110, Farroupilha. CEP: 90040-060.

2 Universidade Federal de Santa Catarina. Florianópolis, Santa Catarina, Brasil. Coordenação do Curso de Graduação em Letras Libras. Centro de Comunicação e Expressão. Sala 137 - Bloco A, Campus Trindade. CEP: 88040-900. 


\begin{abstract}
The present article starts from the perspective of cultural history in the direction of the Deaf Studies. We aim to examine theoretical research that enables the vision of cultural history to be captured in everyday life, the resistances and doings in the culture, in our case, of the deaf people. In these theoretical studies we observed the role deaf culture plays, permeated by the construction of identity, by the Sign Language and the deaf pedagogy. And in contact with that cultural history we noticed a methodology that emphasizes the importance of deaf people participation in this construction. Such history reveals the knowledge in which memories of experiences about 'being deaf' come into scene, with a comprehensive view about what happens with deaf people, especially the bodies gagged by institutional policies, the conflicts in the colonialism field and the educational oppressive systems, the struggles for identity and cultural meanings. These contributions become frequent evidence of subjectivistic signs and meanings. The challenge is to build a new cultural history, registering the struggles for deaf identity, for the construction of a cultural identity, for the recognition of the Sign Language, for the emancipation of deaf subjects from all forms of oppression and their free and spontaneous development as well as for the pedagogy to deaf people.
\end{abstract}

Keywords: history; culture; deaf culture; historical agents; subjectivity; empowerment.

A história cultural contemporânea parece derivar não apenas do enfraquecimento dos antigos modelos que imperavam nas grandes estruturas da História, mas de um possível suporte que a Antropologia e a Linguística lhes oferecem, mudando os imperativos e, consequentemente, favorecendo uma maior consciência acerca da imensa variedade e amplitude das sociedades humanas. Nota-se que as fragmentações acompanham a história cultural, ou seja, os grupos, comunidades, etnias de margens e de fronteiras. E a história é pensada em termos de tensões, relações e conflitos.

Desenvolvendo-se neste ambiente, a história cultural se impõe como novo campo de pesquisas com possibilidades infindáveis. Ela se insere cada vez mais como domínio de saber em que, de acordo com pesquisadores, ocorreram rupturas epistemológicas profundas. Daí ela se encaixar nas camadas sociais, enfatizando os aspectos de sociedades em que as identidades diferenciadas rompem com a questão de serem "construídas para durar eternamente".

E a história cultural pode muito bem ser adotada como campo de investigação da história dos surdos, por ser este um novo campo de saber, o que mais precisamente produz outros modos de relações de poder, bem como de signos de cultura, como: as negociações, investidas pela língua de sinais, pela 
educação, pela diferença de ser, por agrupamentos de lutas e reivindicações, por associações. Estes estão passíveis de ser investigados pela história cultural. Daí ser um desafio contemporâneo fazer uso desta para o registro de aspectos históricos dos surdos.

Neste momento em que vem diminuindo ou sendo alterada a participação dos surdos na história da cultura ou mesmo em programas de história social e de história econômica no país e no mundo, mais do que nunca, podemos nos concentrar na história cultural como campo de saída.

Continuam em nossos meios os métodos de investigação do passado, sendo desconsiderados os métodos de registro da história do presente cultural dos surdos. Estamos, então, diante das possibilidades abertas pela história cultural, mas sem deixar de mostrar que há limites históricos.

Este encontro e a indagação sobre o que seria a nossa própria história cultural e sobre seu possível desfecho nos leva a fazer uma pausa e a perguntar também em que o âmbito desta história seria útil aos surdos, no momento em que a tarefa de construção de nossas identidades diferenciadas surge no ar. Então aparecem as perguntas: com a história cultural nos aventuramos a capturar nossa vida, nossa diferença, nosso jeito de ser? E em que processos ela privilegia conter a mudança necessária como suporte para que uma direção seja determinada e para desmontar definitivamente a história que construíram para nós?

As habilidades exigidas para enfrentar o desafio de adentrar neste campo de investigação requereram buscas em diferentes autores. A observação e a ideia de nos atermos no construir a história de uma forma "essencial" é incômoda e desconfortável. Não pretendemos segui-la. O que nos invade e instiga é que hoje, diante da cultura do agora, nos lançamos com algum objetivo. Pretendemos, então, buscar e seguir as pistas da história cultural como ponto de partida para que a história de surdos tome rumos culturais.

Enfim, como nos foi dito, a história ensina, privilegiando a mudança dos processos sociais, modificando as perguntas, os rumos, as lutas, os projetos e as políticas de então.

\section{O que vem a ser a história cultural dos surdos?}

Os paradigmas deslocados da história geral se concentraram em novo agrupamento. Diante disto, a história cultural dos surdos acompanha devidamente seus caminhos, pois está presente no mundo todo. Tudo que tem história surda, ou antes, ligações típicas agregadas num conjunto de códigos, é passível 
de investigação pela história cultural. Sandra Pesavento ajuda-nos, iniciantes que somos, a refletir sobre a questão. E deixa em aberto as possibilidades bem como os seus limites. Muitas mudanças foram ocorrendo nas pesquisas, nos procedimentos e nas abordagens dos estudos históricos, o que, aliás, repercutiu num verdadeiro debate entre "modernos" e "pós-modernos".

As principais mudanças epistemológicas decorrentes da história cultural estiveram ligadas à reorientação da postura do historiador. Neste sentido, a historiografia surda segue os parâmetros da desconstrução de Derrida, a arqueologia de Foucault, a teoria cultural recente, pois tem seu percurso metodológico aberto para a possibilidade de construir as diferenças, explorar as identidades e alteridades surdas. E este movimento de busca vai se constituindo no "novo fazer".

Anular o passado e requerer o presente se mostrou como artefato cultural para os surdos. Um passado imerso na obrigação de serem ouvintes e, em função disto, aceitar que os outros fizessem a sua história, os dominassem, se tornou a marca mais deprimente. Diante disto, surgem novos feitos e novas interpretações no cotidiano. Neste sentido, se prosseguirmos com as velhas realidades, narradas como que no tempo colonial, perigamos escrever uma história de holocausto, de dominação, de lamentos. Mas não é por aí... Temos outros caminhos que, mesmo desconhecidos, merecem ser trazidos à tona, vivenciados e narrados por constituírem a genuína história natural e cultural dos surdos. De fato, temos nossas lutas de significação quais sejam: a busca por educação bilíngue, por políticas para a língua de sinais no Brasil, pela abertura das portas das universidades, por posições de igualdade, por ter intérpretes de língua de sinais e por serem válidos os nossos direitos. Além desses, há muitos espaços que possibilitam novos signos e significados que nos motivam, estando presentes em nosso cotidiano e que nos trazem algo mais desejado - encarnar essas possibilidades "como pessoas completamente diferentes".

Então a história cultural dos surdos é possível e presente? A partir da declaração de Pesavento, sim! A importância desta história é o que ela leva em conta: "[...] a subjetividade dos atores a resgatar no passado. Uma das características da História Cultural foi trazer à tona o indivíduo, como sujeito da História, recompondo histórias de vida, particularmente daqueles egressos das camadas populares" (2005, p. 118).

Esta afirmativa de Pesavento vai de encontro à questão foucaultiana em que os sujeitos marginalizados, de fronteira, de periferia conseguem reverter a história e esta vir à tona, não como um incômodo, mas como necessidade para sua presença social. A partir desta afirmativa podemos olhar para o que temos: as narrativas históricas dos surdos. Estas se descortinam como um campo aberto. E para registrar a nossa história cultural sentimos a necessidade de adentrar os feitos culturais e linguísticos dos povos surdos para capturar o ritmo histórico 
das comunidades surdas existentes hoje. A história cultural é um campo de saber recente, como também assinala Pesavento:

[...] com a mudança nos anos 1970 ou mesmo um pouco antes, com a crise de maio de 1968, com a guerra do Vietnã, a ascensão do feminismo, o surgimento da New Left, em termos de cultura, ou mesmo a derrocada dos sonhos de paz no mundo pós-guerra. Foi quando então se insinuou a hoje tão comentada crise dos paradigmas explicativos da realidade, ocasionando rupturas epistemológicas profundas que puseram em xeque os marcos conceituais dominantes na História (2005, p. 8).

A história cultural é uma nova interpretação de caminhos percorridos, para a deferência do povo surdo, dando lugar à sua cultura, valores, hábitos, leis, língua de sinais, bem como à política que movimenta tais questões, e não mais a excessiva valorização da história registrada sob as visões do colonizador, uma história que dá lugar ao sujeito. Ela não interpreta o sujeito como algo fora de contexto, inventado, mas o sujeito como instrumento histórico no sentido e no significado.

Entre nós, a história cultural não é aquela que contém a feia sina, como acontece atualmente, em que os aportes são registrados em alguns livros, teses e dissertações de forma resumida, elencada, esquematizada, repetindo ao infinito sempre as mesmas peripécias do colonizador. Estas são histórias que sempre trazem o olhar daquele sobre o surdo e que, muitas e muitas vezes, voltam ao passado em que apenas formas de lideranças sobre o corpo surdo são registradas ${ }^{3}$. Dessa forma continuam esquecidos os atores históricos surdos, esquecem-se as subjetividades e as questões que poderiam muito bem ser registradas dentro dos limites da história cultural. Estes limites se estabelecem pela diferença de identificação histórica e pela diferença de sujeitos e métodos próprios de captação de dados.

\section{Interlocuções da história cultural dos surdos}

Analisando o conjunto das produções de história cultural, notamos que ela se insere no contexto acadêmico, em agremiações, movimentos de luta, cam-

3 Neste contexto podemos elencar o Congresso de Milão, o oralismo, os métodos de correção que Foucault (2004, p. 29) cita como sendo tecnologia de poder sobre o corpo, a tecnologia da "alma" dos educadores, dos psicólogos e dos psiquiatras. 
peonatos, educação, bem como em imagens como fotografias, cinema, filmes, desenho, computação gráfica e outros. Diferentes linguagens, diferentes locais de captação. Captar as diferentes formas e linguagens que a elucidam é uma tarefa estafante. Barros nos dá pistas sobre estes caminhos da história cultural:

[...] ela abre-se a estudos os mais variados como a "cultura popular", a "cultura letrada", as "representações", as práticas discursivas partilhadas por diversos grupos sociais, os sistemas educativos, a mediação cultural através de intelectuais, ou a quaisquer outros campos temáticos atravessados pela polissêmica noção de 'cultura' (2004, p. 55).

Aqui é preciso pontuar a necessidade da diferenciação entre a linguagem da história geral e a linguagem do colonizado. Se nos ativermos verdadeiramente à linguagem do colonizador e à do colonizado, conseguiremos diferenciar. A performance contém ambivalências; daí a formalidade e a riqueza de tais pressupostos. Se o colonizador está à espreita de todas as ocasiões para submeter o colonizado, o colonizado está em busca das ocasiões para construir sua trajetória de sujeito. Neste momento, ele pode estabelecer redes de poder que lhe deem a autonomia de construir sua história na diferença.

Este artefato histórico enfoca a cultura e atesta a presença e a passagem do sujeito surdo através de tempos e espaços. Ele se reporta a ela como tipo de linguagem recheada de interlocuções, que partilha a condição de ser simbólica, ou seja, é portadora de significados para além daquilo que produz: certa nostalgia.

A história cultural oferece a nostalgia. Ela se incumbe de um tipo de representação que perpassa a trajetória humana e se coloca num lugar de cruzamento no qual experiências vividas se entrelaçam com as experiências presentes. Isto equivale a dizer que nostalgias animam novamente os elos vitais e a predisposição para a aquisição simbólica que mantém o sujeito no tempo mediante a força de saber. As nostalgias são capturas de acontecimentos simbólicos do passado em linguagem presente.

\section{Caminhos do historiador}

Tentar resgatar e, principalmente, entender como os surdos de outros tempos e dos tempos atuais dão sentido ao mundo e o transformam a fim de 
fazê-lo habitável, como o entendem, como se relacionam, como negociam a cultura nas relações de poder, como acontecem as intercorrências, como dão sentido ao mundo, é uma das lides do pesquisador e historiador. Mas também, compor tramas, colher enredos, presumir desfechos, situações acontecidas e acontecendo no tempo, inexplicáveis por vezes. Pesavento (2005) de novo explica sobre o historiador.

\begin{abstract}
Mas no campo da História Cultural, o historiador sabe que a sua narrativa pode relatar o que ocorreu um dia, mas que esse mesmo fato pode ser objeto de múltiplas versões. A rigor, ele deve ter em mente que a verdade deve comparecer no seu trabalho de escrita da História como um horizonte a alcançar, mesmo sabendo que ele não será jamais constituído por uma verdade única ou absoluta. $\mathrm{O}$ mais certo seria afirmar que a História estabelece regimes de verdade, e não certezas absolutas (2005, p. 51).
\end{abstract}

A história estuda processos, privilegia registrar a mudança e traz lições para o cotidiano. Assim, as lutas, os passos para procedimentos de relações de poder e negociações se tornam possíveis. Os historiadores surdos, bem como historiadores ouvintes mudaram, mudaram as percepções, as análises, os problemas, os focos. Não mais é o corpo dominado no passado, mas as motivações criadoras acontecidas, produtoras de novas narrativas, novos achados, novos focos.

O campo das experiências históricas surdas, entendidas como dignas de serem narradas, expandiu-se juntamente com a incidência dos novos temas de estudo. Tais narrativas vêm de inúmeras práticas surdas na luta pelo poder, antes silenciadas, de novos sujeitos surdos e novos perfis para serem incluídos no discurso histórico. Partiram inicialmente das narrações de pesquisadores surdos, militantes e líderes, para incluir, em seguida, as dos trabalhadores, dos desempregados surdos, entre outras. Com a vinda do direito a contribuir para a sociedade em que vivemos, o direito à história e à presença da memória passou a ser integrado ao discurso do processo de produção do conhecimento.

\title{
Compreendendo a cultura surda como movimento e espaço de história
}

Se nos ativermos ao mundo pós-moderno e às definições de cultura, notaremos que estamos, praticamente, saindo dos centrismos e das denominações 
de alta, baixa, má cultura e nos referindo às diferentes culturas. É praticamente aquilo que denominam de periférico, marginal, fronteiriço.

A intenção de trazer para este espaço a cultura surda, uma cultura contestada e periférica, e captar como ela adentra como espaço da história cultural, é necessária. Este aspecto nos motiva a prosseguir nas investigações, nos dá um recorte amplo da nossa pesquisa e é um caminho imprescindível.

Então, acompanhando variações de estudos sobre a cultura, de tradicionais até atuais, encontramos o conceito de cultura transmitido e interiorizado em diferentes aspectos, assim como Moles (1967 apud RICOU; NUNES, 2001) afirma: "cultura, termo tão carregado de valores diversos que o seu papel varia notavelmente de um autor para outro e do qual se enumeraram mais de 250 definições". Também Perlin explica o conceito de cultura:

Os diferentes conceitos de cultura estão aí para se compreenderem as diferentes posições de cultura. Há conceitos unitários de cultura; conceitos de alta cultura e baixa cultura; conceitos referentes a múltiplas culturas. Há algumas posições mais radicais diante das culturas, por exemplo, de grupos que compartilham da afirmação de uma cultura universal onde legitimam a dominação das outras culturas. [...] Na temporalidade pós-moderna, perdemos o "conforto" de pensar a cultura como algo global, único em conceitos de diferentes culturas ou múltiplas culturas. O que significa a cultura no espaço pós-moderno presente, na temporalidade em que vivemos? O conceito pós-moderno coloca o problema como sempre: diferenças culturais, múltiplas culturas. $\mathrm{O}$ conceito de cultura igualmente muda e mesmo pode oscilar, sendo entendido dentro de novas tramas epistemológicas. Entramos, portanto, na presença de diferenças culturais, diferentes culturas, cada uma com sua emergência, sua história, seus usos, suas particularidades (2004, p. 74-75).

Em seu livro "As imagens do outro sobre a cultura surda", a também pesquisadora surda, Strobel, cita:

Cultura surda é o jeito de o sujeito surdo entender o mundo e de modificá-lo a fim de torná-lo acessível e habitável, ajustando-o com as suas percepções visuais, que contribuem para a definição das identidades surdas e das "almas" das comunidades surdas. Isto significa que abrange a língua, as ideias, as crenças, os costumes e os hábitos do povo surdo (2008, p. 22). 
Para compreender melhor, temos um exemplo que se pode comparar com a cultura surda. Os autores Freeman, Carbin e Boese a colocam na posição similar à de um outro grupo totalmente diferente na sociedade, o dos soldados. Eles têm uma perspectiva de vida, na sociedade, diferente da dos civis. Apreciam conversar sobre os assuntos em comum como bombas, armas, paraquedismo etc. É obvio que, de diversas maneiras, eles são mais ou menos parte da cultura de seu país. Podem ter muito em comum com os soldados de outros países e juntos se sentirem mal compreendidos ou pouco apreciados pelos civis e, ao mesmo tempo, sentem orgulho na prática de atividades desconhecidas para muita gente (1999).

Nessa linha de raciocínio, afirma a pesquisadora surda, Perlin, que as atitudes fazem com que os surdos se identifiquem ao mundo visual próprio deles:

É o caso de ser surdo homem, de ser surdo mulher, deixando evidências de identidade, o predomínio da ordem, como por exemplo, o jeito de usar sinais, o jeito de ensinar e de transmitir cultura, a nostalgia por algo que é dos surdos, o carinho para com os achados surdos do passado, o jeito de discutir a política, a pedagogia etc. (2004, p. 77).

Assim como ocorre com as diferentes culturas, a cultura surda é o padrão de comportamento compartilhado por sujeitos surdos na experiência trocada com os seus semelhantes quer seja na escola, nas associações de surdos ou encontros informais. Isto origina a identificação de pertencer a um povo distinto, caracterizado por compartilhar língua de sinais, valores culturais ${ }^{4}$, hábitos e modos de socialização, e que, conforme reflete Hall (2004), é a representação que atua simbolicamente para classificar o mundo e nossas relações no seu interior. Novamente descreve a pesquisadora surda:

[...] As identidades surdas são construídas dentro das representações possíveis da cultura surda, elas moldam-se de acordo com a maior ou menor receptividade cultural assumida pelo sujeito. E dentro dessa receptividade cultural, também surge aquela luta política ou consciência oposicional pela qual o indivíduo representa a si mesmo, se defende da homogeneização, dos aspectos que o tornam corpo menos habitável, da sensação de invalidez, de inclusão entre os deficientes, de menos-valia social. (2004, p. 77-78)

4 Valores culturais: significados culturais feitos a partir do uso do olhar, entre eles a língua de sinais, o jeito de ser, de ensinar, de comunicar, etc. 
No contexto do povo surdo, os sujeitos não distinguem um de outro de acordo com sua surdez. O mais importante para eles é o pertencimento ao povo surdo por meio do uso da língua de sinais e da cultura surda, que os ajudam a definir as suas identidades. Portanto, ser surdo de nascença é muito respeitável na comunidade surda:

A partir de uma visão dos Surdos, o ato politizado de alegar uma surdez "nativa" - ou seja, uma surdez de nascença - está ligado à identidade positiva de não estar "contaminado" pelo mundo dos que ouvem e suas limitações epistemológicas do som seqüencial. A "pureza" do conhecimento dos Surdos, a verdadeira Surdez, que vem da expulsão desta distração é na cultura dos Surdos uma marca de distinção. Seria melhor ainda se os familiares e até mesmo seus pais fossem também Surdos (WRIGLEY, 1996, p. 15).

Mas como observamos, o povo surdo recebe o nascimento de cada criança surda como um presente valioso e não age como os pais ouvintes que toleram, sem disfarçar, a desilusão inicial de terem gerado um filho surdo.

Quando o médico apresenta o diagnóstico da surdez, os pais ficam chocados, deprimem-se e culpam-se por terem gerado um filho dito "não normal" e ficam frustrados porque veem nele um sonho desfeito. Então, essas famílias alimentam esperanças de "cura" dessa "deficiência", ficam ansiosas e questionam: será que o meu filho surdo um dia ouvirá? (STROBEL, 2008a, p. 48).

Dentro da história cultural dos surdos há vários artefatos culturais como a experiência visual, a linguística, a literatura surda, a vida social e esportiva, as artes, políticas e outros. " "[...] o conceito 'artefatos' não se refere apenas a materialismos culturais, mas àquilo que na cultura constitui produções do sujeito que tem seu próprio modo de ser, ver, entender e transformar o mundo" (STROBEL, 2008a, p. 35).

Para o sujeito surdo ter acesso a informações e conhecimentos e para estabelecer sua identidade é essencial criar uma ligação com o povo surdo o qual usa a sua língua em comum: a língua de sinais.

Ela é uma das principais marcas da identidade de um povo surdo por ser uma das peculiaridades da cultura surda. É uma forma de comunicação que capta as experiências visuais dos sujeitos surdos, sendo que é esta língua que

5 Para saber mais sobre os artefatos, ler: Strobel (2008a). 
vai levar o surdo a transmitir e proporcionar-lhe a aquisição de conhecimento universal (STROBEL, 2008a, p. 42-43).

A língua de sinais vem assumindo um lugar cada vez mais relevante, não só nas pesquisas, mas também nas comunidades surdas. Embora se encontrem registros de que já no século XVIII se reconhecia a importância da Língua de Sinais, foi somente no século XX, nos anos 1960, que tiveram início os primeiros estudos linguísticos sobre ela.

Mesmo que, por muitos anos, tenham proibido os surdos de usar a língua de sinais, ela sobreviveu graças à resistência contra a prática ouvintista; muitas crianças em escolas para surdos, quando sua língua era proibida, a praticavam às escondidas entre si, assim como relata esta autora surda sobre o período durante a sua infância na escola de surdos:

Quando um dos professores se virava para escrever no quadro-negro, tínhamos hábito de trocar informações na língua de sinais, persuadidos de que ele não nos escutava, já que não nos via. Ora, no começo, ele se voltava todas as vezes, era estranho, não compreendíamos imediatamente por quê. Com o passar do tempo, dei-me conta de que, ao falar com as mãos, sem saber, emitíamos ruídos com a boca. Cuidamos então de não mais emitir nenhum som e, desde aquele dia, trocamos nossas lições o mais tranqüilamente possível (LABORITT, 1994, p. 84).

E, então, que isto de pertencimento ao povo surdo leva a constituir uma política conjunta de luta por valores. Povo, por si mesmo, sempre é um movimento, algo que se firma, que não para, que evidencia suas lutas, seus direitos, suas estratégias. E a história vai-se constituindo em meio a este "que fazer". Vai surgindo uma condição histórica dentro do espaço dos surdos. Vai-se fazendo em direção ao movimento interno de ser.

\section{A história cultural como campo de saber e de poder}

Em termos históricos, a metade do século XX constituiu o marco da descontinuidade e as diferenças surgem como formas do exercício do poder. Consequentemente, uma série de empoderamentos vai tomando formas entre os surdos. A intenção aqui não é elencar estas conquistas, mas trazer presentes 
significações históricas, pensar este empoderamento transparente e imprescindível que faz acreditar em sua influência.

A história cultural no uso de suas ferramentas, ao ser manuseada e usada de forma convincente, aborda e proporciona conceitos novos? Devidamente, o objetivo da história cultural é transparente. Ela é tomada aqui como processo discursivo, como reinvenção de linguagem, de fatos acontecidos no passado com signos e significados marcantes. Significados estes que se articulam como jogo de poder e saber, o que nem sempre a história, que o colonizador escreve e conduz, consegue atingir.

Em rápidas palavras, aquilo a que se dispõe a história geral dos surdos está condicionado a uma leitura com tendência à interpretação e à compreensão por meio dos professores de surdos e a luta pela educação, como memória disciplinar, contra o esquecimento dos líderes surdos e sua não presença ${ }^{6}$ na história. Estes signos, se possuidores de sensação de impotência, de deficiência, de marginalização, levam à melancolia, levam também a questões de deficiência para que se continuem as imposturas do colonizador e, em alguns casos, à revolta do colonizado ou demência deste. Ela tira de circulação o colonizado.

Em meio à simultaneidade e às diferentes mutações que acontecem, as propostas de uma pedagogia da história cultural são evidentes. A possibilidade de subjetivação se aproxima e se distancia com formações discursivas, evidenciando a presença do sujeito em si. No caso dos surdos, evidencia o sujeito, não o construído, mas o sujeito em si. Ela reflete sobre os próprios reflexos do sujeito, de sua compleição, suas narrativas e estratégias de sobrevivência, necessidades, direitos e leva o sujeito ao encontro de si.

Esta segunda corrente historiográfica se ocupa com a leitura das narrativas correspondentes ao sujeito e pelo sujeito e, consequentemente, o que é contemporâneo a ele num espaço com traços de passado.

Notadamente, o discurso histórico-cultural entende e identifica o sujeito em sua presença nos grupos. E estes grupos são dados a perceber aparecendo como redutos de tradução da realidade por meio das narrativas, o que os torna participantes da história. Neles percebem-se razões e sentimentos que movem tais sujeitos e que denotam suas práticas sociais.

Trata-se de um discurso que, operando pela probabilidade e não pela veracidade, cita os efeitos da verdade. Em resumo, a história cultural é uma narrativa que se nomeia como verdadeira e mesmo se situa no passado, tomando o seu lugar como reveladora dos movimentos em sua caminhada histórica. Ela leva ao discurso arbitrário e à certeza de um compromisso comum por uma causa, e à busca de um

6 Enquanto na história, aqueles professores ouvintes que fizeram a educação dos surdos são presentes, já a contribuição dos professores surdos continua desconhecida, dificultando também a sua compreensão e, mais que tudo, com os problemas subjetivantes daí decorridos. 
ponto de referência que une o líder e a marcha a uma direção inquestionável e com um objetivo comum. Nesse aspecto, o discurso da história cultural chega a atingir um resultado de autenticidade. Os estudos da história cultural, no dizer de Pesavento, Santos e Rossini (2008, p. 11), se distinguem dos estudos que privilegiavam as manifestações da alta cultura com os quais se confundem alguns momentos.

Para entender como estas relações de poder e de saber "atravessam" a história cultural é interessante recorrer a Foucault:

Temos que admitir que o poder produz saber [...]; que poder e saber estão diretamente implicados; que não há relação de poder sem constituição correlata de um campo de saber, nem saber que não suponha e não constitua, ao mesmo tempo, relações de poder. Essas relações de "poder-saber" não devem, então, ser analisadas a partir de um sujeito de conhecimento que seria livre ou não em relação ao sistema de poder; mas é preciso considerar ao contrário que o sujeito que conhece, os objetos a conhecer e as modalidades de conhecimentos são outros tantos efeitos dessas implicações fundamentais do poder-saber e de suas transformações históricas. Resumindo, não é a atividade do sujeito do conhecimento que produziria um saber, útil ou arredio ao poder, mas o saber-poder, os processos e as lutas que o atravessam e que o constituem, que determinam as formas e os campos possíveis de conhecimento (1987, p. 30).

Notadamente, se quisermos construir a história cultural do surdo, ao invés de procurar causas técnicas e estruturais específicas, estudaremos o discurso a partir do qual o poder saber foi estabelecido, segundo o surdo, o que deve produzir uma análise crítica mais aprofundada das interpretações históricas decorrentes. É, então, que se entende o povo surdo, se compreende o registro dos momentos em que a diferença cultural foi marcante, bem como as produções de significação, de diferenciação linguística e de pertencimento. E nisto o saber dá visibilidade, investimento, e tendência. Tanto mais quanto os historiadores continuem empenhados nesta aventura do conhecimento.

\section{Finalizando com novas formas e perspectivas}

O trabalho do historiador é exercer a performance da história cultural dos surdos por meio de intercorrências culturais. Nela o sujeito não será racional, 
mas simbólico, presencial. Nela transparece a narrativa na qual o mito se aloja numa temporada. Ela se dispõe a acordar o percurso e o discurso políticos do sujeito surdo em vista das tramas sociais. O trabalho do historiador é o de mostrar o acontecido, o herói e a heroína encadeados, para divulgar a regeneração da raça surda contra a obrigação de narrar-se um ser diverso, e fazer surgir a lógica da diferença cultural e as produções de significação, pertencimento e diferenciação. A história cultural registra os feitos, os discursos, o histórico não em simples manifestações culturais, mas em símbolos de manifestações, estratégicos e culturais, com significados subjetivantes.

As possibilidades abertas para os estudos históricos dos surdos pela história cultural são inúmeras e profundamente instigantes: desde a desconstrução dos temas e interpretações ouvintes às novas propostas de se sinalizar como sujeitos das experiências do cotidiano, da história, dos detalhes, do mundo experienciado, da ruptura com as oposições binárias e de dentro, incorrendo nos campos dos Estudos Culturais.

A história cultural se apresenta como importante caminho, tanto assim que ela em seus contextos vai captar signos e significados subjetivantes que conduzem o sujeito ativo ao seu próprio processo.

Em suma, a história cultural é um lugar onde podemos guardar os sentimentos e os pensamentos para despertar, animar e incentivar a coragem, constância e outros valores com os quais o povo surdo luta e sente-se como um todo único. É ela que não apaga a história e mantém o caráter vivo, tendo em vista suas indagações, representações, empenho e o sonho do futuro.

\section{REFERÊNCIAS}

BARROS, J. D. A. O campo da história: especialidades e abordagens. Petrópolis: Vozes, 2004.

. O projeto de pesquisa em história. Petrópolis: Vozes, 2005.

FOUCAULT, M. Vigiar e punir: história das violências nas prisões. 5. ed. Petrópolis: Vozes, 1987.

FREEMAN, R. D.; CARBIN, C. F.; BOESE, R. J. Seu filho não escuta? Um guia para todos que lidam com crianças surdas. Brasília: Gráfica Valci Editora, 1999.

HALL, S. A identidade cultural na pós-modernidade. Rio de Janeiro: DP\&A, 2004.

LABORITT, Emmanuelle, O vôo da Gaivota. São Paulo: Best Seller, 1994. 
PERLIN, G. O lugar da cultura surda. In: THOMA, A. da S.; LOPES, M. C. (Orgs.). $A$ invenção da surdez: cultura, alteridade, identidade e diferença no campo da educação. Santa Cruz do Sul: EDUNISC, 2004.

PESAVENTO, S. J.; SANTOS, N.; ROSSINI, M. (Orgs.). Narrativas, imagens e práticas sociais: percursos em história cultural. Porto Alegre: Asterisco, 2008.

PESAVENTO, S. J. História \& história cultural. Belo Horizonte: Autêntica, 2005.

RICOU, M.; NUNES, R. Comunidade surda: que futuro? Texto de Conferência do Departamento de Bioética e Ética Médica da Faculdade de Medicina da Universidade do Porto no Seminário organizado pela ASPorto em 5 de maio de 2001. Disponível em: $<\mathrm{http}: / /$ www.feneis.org.br/Libras/portugal/comunidade_futuro.htm>. Acesso em: 28/06/2009.

STROBEL, K. As imagens do outro sobre a cultura surda. Florianópolis: Editora da UFSC, 2008a.

. História de educação dos surdos. Texto-base de curso de Licenciatura de Letras/ Libras, UFSC, Florianópolis, 2008b.

WRIGLEY, O. Política da surdez. Washington: Gallaudet University Press, 1996.

Texto recebido em $1^{\circ}$ de julho de 2014. Texto aprovado em 07 de agosto de 2014. 
